\title{
A Hierarchical Self-organised Classification of 'Multinational' Corporations
}

\author{
Khurshid Ahmad ${ }^{1}$, Chaoxin Zheng ${ }^{1}$, and Colm Kearney ${ }^{2}$ \\ ${ }^{1}$ Department of Computer Science, Trinity College, Dublin \\ ${ }^{2}$ School of Business Studies, Trinity College, Dublin \\ kahmad@cs.tcd.ie, chaoxin.zheng@cs.tcd.ie, colm.kearneyatcd.ie
}

\begin{abstract}
Classification of entities, for example, into national states, into social groups, into business enterprises and into scientific taxa, is an enduring problem in neural computing. In this paper, we look at the problems faced by researchers in developing a taxonomy of 'multinationality' and explore the use of hierarchical SOMs in 'discovering' a taxonomy of multinational corporations (MNCs).
\end{abstract}

Keywords: Hierarchical Self Organising Maps, Multinational Corporations.

\section{Introduction}

Financial engineering has seen a number of applications of neural networks. These systems have been used: (a) for classifying of investment opportunities (Yu, Wang and Lai 2008); (b) in predicting the behaviour of markets (McNeils 2005, TaskayaTemezil, Casey and Ahmad 2005); \& (c) for categorizing large number of financial texts (Manomaisupat, Vrusias \& Ahmad 2006).

In this paper we will look at the role of neural networks in the classification of entities discussed in the literature on the theory of the firm where problems of taxonomic organization are at the forefront. We look at the classification of 'multinational' corporations (MNCs) based on their multifaceted attributes. The compilation of the attributes requires acquisition and metrication of data relating to a corporation's 'engagement with and exposure to' domestic, regional, trans-regional and global markets (Aggarwal, Berril and Kearney, forthcoming).

\section{Motivation: Towards a Taxonomy of Multinational Corporations}

The classification of corporations is an important issue in business and finance both in terms of the conceptual basis of such a classification and in terms of the practical import of the evolution, sustenance and obsolescence of this critical component of economies large and small. Scholars of finance in general, and international business and international marketing in particular, have stressed the need for a taxonomic classification of multinational companies (see, for example, Barry and Kearney 2006). 
The multinational corporation has a number of facets: An MNC conducts research, is involved in marketing and sales, and invests across geographical and political boundaries. An MNC maintains a 'main' or 'head' office in one particular location, it sends its key managers to parts of the world that have different political and cultural values and systems. Researchers in international business are interested in quantifying: (a) what happens in the offices of an MNC 'abroad' by using performance attributes of an MNC; (b) what financial and physical resources are deployed away from 'home', by using the structural attributes; and, (c) how well an MNC is or will be performing by using attitudinal attributes. The reliance on one single attribute, for example foreign sales as a percentage of total sales, to measure the degree of internationalisation of an MNC, makes such a measurement very vulnerable to the inevitable errors in the values of the single attribute. Nevertheless, a review of over 100 papers, published between 1970 to 2006, on the topic of classifying MNCs, shows that just about half the researchers have used a single variable, whilst the other half conducted multivariable studies (Aggarwal, Berrill and Kearney, forthcoming). We intend to find out whether the use of self-organising maps has a role in classifying MNCs.

\section{A Note on Hierarchical SOMs}

A self-organising map (SOM) is used to map high-dimensional observations onto a lower dimensional map whilst preserving the topological relations between the represented objects with a degree of fidelity. The SOM algorithm is based on a winnertakes-all-strategy where individual nodes in the low-dimensional map 'win' the right to represent objects in the high dimensional space. The SOM seldom produces discernible clusters and it is important to analyse the output of an SOM using other clustering techniques to ascertain the presence or absence of clusters in the output (see, for example Ahmad, Vrusias and Ledford 2001).

The hierarchical SOM (HSOM), proposed originally by, amongst others, Lampinen and Oja (1992), comprises $n$ independent SOM's organised in layers. The first layer is trained using an input feature vector. Once trained, the winning nodes in the first map act as input to the next layer and so on. The hierarchical map then helps in visualizing the input data at different levels of taxonomic organization. The top layer may be used to identify the presence of clusters and the lower levels representing subclusters. It has been argued that an HSOM can be trained more quickly than a single SOM and that HSOM's can be used to map data sets with higher dimensions than is effectively possible with a single SOM (see, Vicente \& Vellido 2008 for an elaborate review on the subject.). An algorithm for training an HSOM is given below.

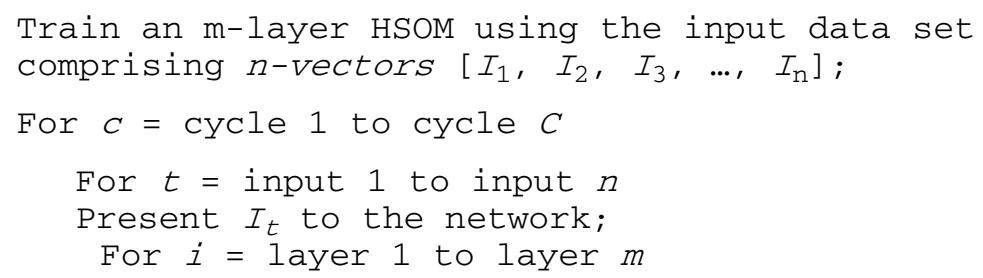




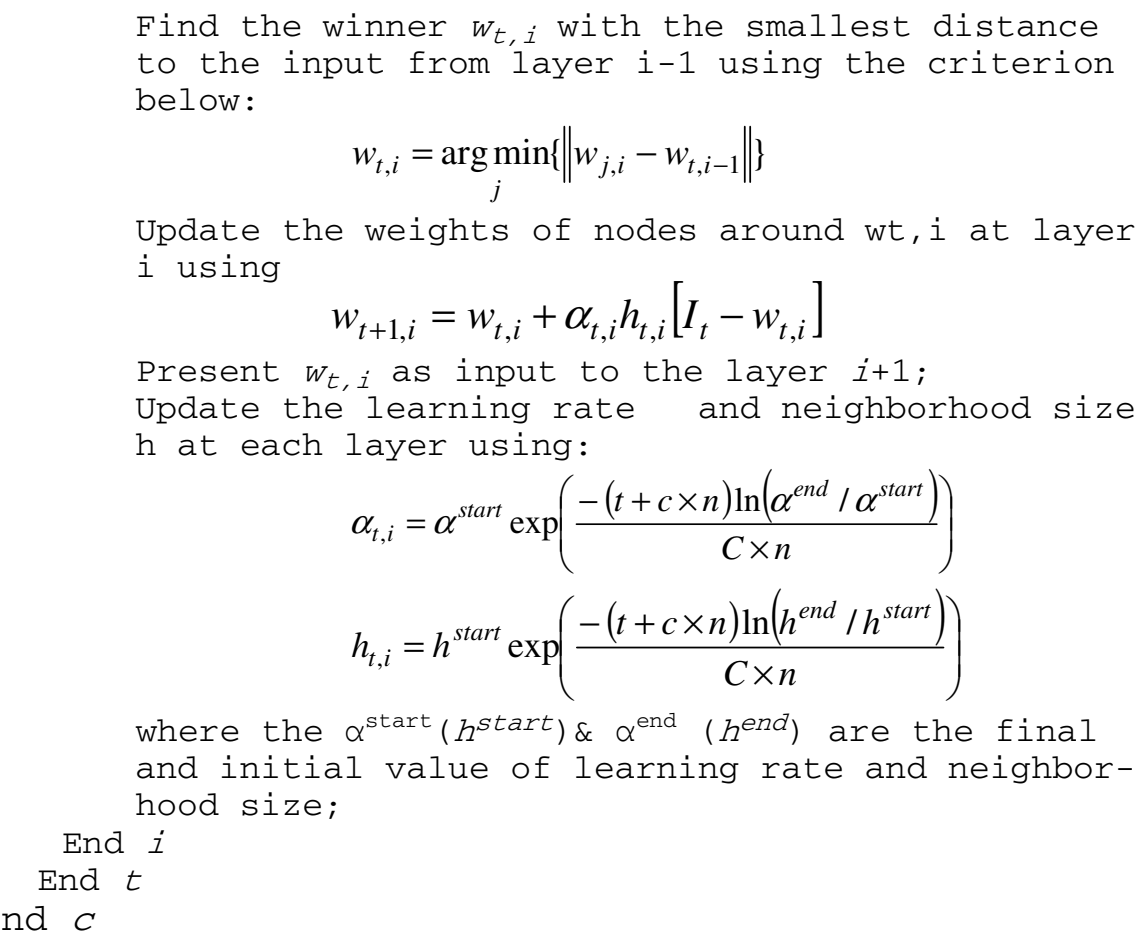

The HSOM used in this paper for the classification of MNCs has three layers comprising $10 \times 10,5 \times 5$, and $2 \times 2$ neurons respectively. The initial neighborhood size for all the three maps is a quarter of the size of the map, decreasing exponentially to finally 1 . The initial learning rates for all the three layers are all set to 0.9 , which is also exponentially decreased to 0.1 .

During training, the feature vectors (representing each of the corporations) are presented to the HSOM one at a time and the training takes over a predetermined number of cycles -10 is the number we have used. During each cycle, the order of presentation of the feature vectors is randomly selected. For testing, a proportion of company data is randomly selected and then used only for testing purposes.

\section{Towards a Multivariate Classification of MNCs}

We will now present two multivariate studies for classifying corporations. The classic study of Sullivan (1994) is repeated using a 3 layer HSOM; we use a data set of 25 corporations, each comprising 5 attributes. This is followed by analyzing a larger and more modern data set created by Aggarwal, Birrel and Kearney. Our data set contains $100 \mathrm{MNCs}$ with 7 attributes per corporation. The case studies are multivariate as in both the cases we look at the variance in the value of two or more attributes. 


\subsection{Case Study I: Multivariate Analysis and Sullivan's Classification of MNC}

Sullivan (1994) has suggested a multivariable study of the measures to compute the degree of internationalization of an MNC.

Table 1. The nine key variables used in Sullivan (1994) divided into three key attributes

\begin{tabular}{|l|l|}
\hline Performance & $\begin{array}{l}\text { Foreign Sales/ Total Sales (FSTS), Export Sales/Total Sales } \\
\text { (ESTS), } \\
\text { Foreign Profits/Total Profits (FPTP), R\&D Intensity (RDI), } \\
\text { Advertising Intensity Performance (AIP) }\end{array}$ \\
\hline Structure & $\begin{array}{l}\text { Foreign Assets/Total Assets (FATA), } \\
\text { Overseas Subsidiaries/Total Subsidiaries (OSTS) }\end{array}$ \\
\hline Attitudinal & $\begin{array}{l}\text { Top Managements' International Experience (TMIE), } \\
\text { Psychic Dispersion of International Operations (PDIO) }\end{array}$ \\
\hline
\end{tabular}

The author has collated data on the nine attributes and performed item analysis (see Field 2005) on these attributes for 74 corporations (see Table 1). This analysis helped in finding that the key attributes, FSTS, FATA, OSTS, TMIE and PDIO, show statistically significant correlation with each other. These results were confirmed by factor analysis. A weighted linear combination of the five attributes was termed degree of internationalization (DOI) and it was found to be distributed normally.

Sullivan (1994: 336) has provided DOI-rankings of 25 companies based on the estimates of the five given attributes and one computed attribute (DOI). We have used this data set to train a hierarchical SOM to explore what kind of clustering we obtain by simply using the rank order of the 5 attributes for the 25 companies. The training set for our HSOM comprised 22 feature vectors each with the rank-order information about the company's FATA, FSTS, OSTS, PDIO and TMIE. The HSOM itself comprises of a root network of 10x10 nodes. This network, which receives the feature vectors, acts as input to the next $5 \times 5$ network in the hierarchy. Finally, the $5 \times 5$ network acts as input to a $2 \times 2$ network. Recall that our system selects about $10 \%$ of the vectors randomly for testing - in the case of Sullivan's 25 corporations, 3 were chosen randomly for testing - American Cyanamid, Avon, and Pfizer.

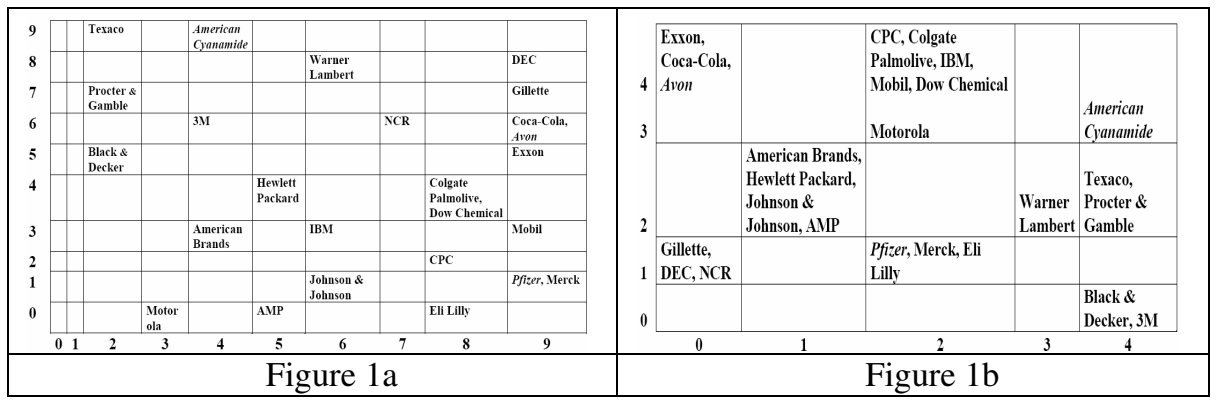

Fig. 1. HSOM Classification - The mapping of Sullivan's 25 companies. Figure1a shows the initial root map (10X10) and the second level (5x5) is shown in Figure $1 \mathrm{~b}$. 
The initial mapping from the 5 dimensional vector onto the 2-dimensional 10x10 surface shows a scatter of the corporations with no significant clusters (Figure 1a). The weights of the winning node in the $10 \times 10$ network are then used to train the $5 \times 5$ network (Figure 1b). This network shows an emergence of some structure with the corporations with highest ranks in FATA and FSTS clustering together. Lastly, the weights of the winning nodes in the $5 \times 5$ network are used in the training of the final $2 \times 2$ map and there is evidence of clustering here.

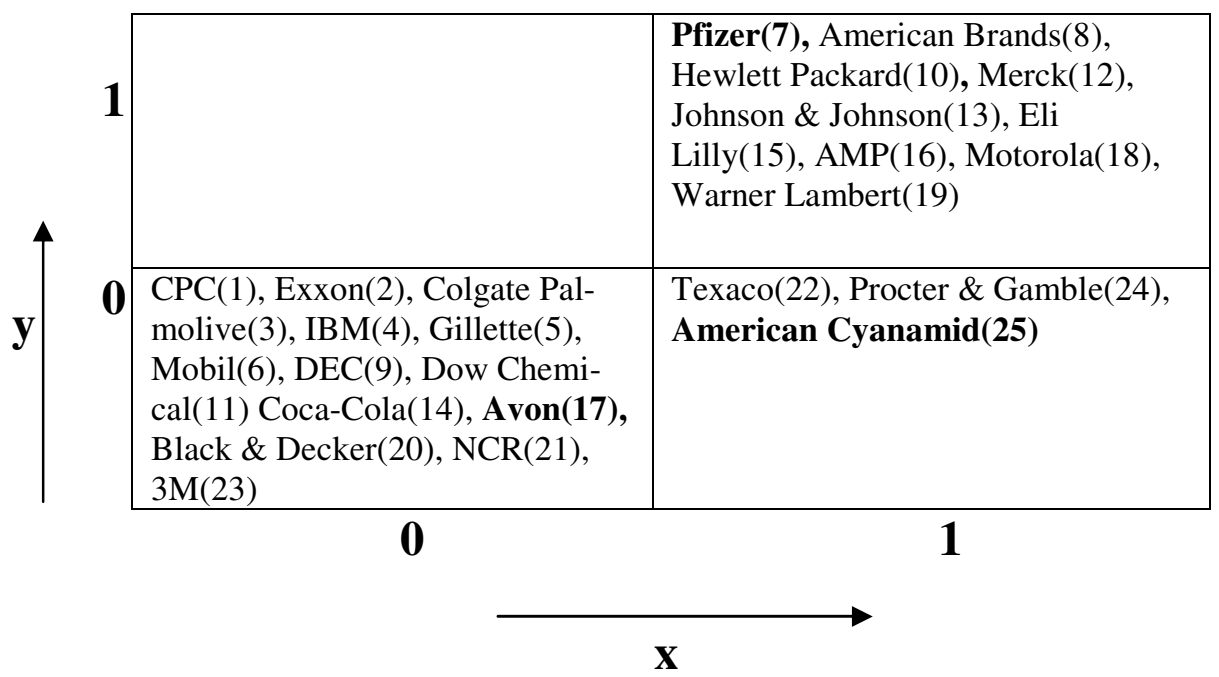

Fig. 2. The final level in the HSOM Classification for MNC data in Sullivan (Numbers in parentheses are the DOI rankings by Sullivan, but were not used in training). The values for FSTS, FATA, OSTS, TMIE and PDIO, were used to train the HSOM. Note that the data related to 3 companies (Avon, American Cyanamid and Pfizer was only used for testing.

The $2 \times 2$ map can be divided into four quadrants that we count clockwise through the $x-y$ co-ordinates $00,01,11$ and 10 as $1^{\text {st }}, 2^{\text {nd }}, 3^{\text {rd }}$ and $4^{\text {th }}$ quadrants. In the $1^{\text {st }}$ quadrant (00, Figure 2), 8 out of the 11 top ranking corporations have been classified together; there are 4 lowest ranked organisations also in this quadrant. The $2^{\text {nd }}$ quadrant (01) is empty. The $3^{\text {rd }}$ quadrant $(11)$ has all intermediate ranking corporations, from $7^{\text {th }}$ to $19^{\text {th }}$. The $4^{\text {th }}$ quadrant (10) has lowest ranked corporations. Test feature vectors (for the corporations Avon (rank 17), Pfizer(7) and American Cyanamid (rank 25)) show that whilst the lowest ranked was classified correctly, the ambivalence of the first and third quarter showed in the assignment of highly ranked corporation (Pfizer) in the intermediate rank cluster, and vice versa for Avon. With the external knowledge of industry type, one can argue that the HSOM has correctly placed Pfizer with other pharmaceutical corporations (Eli-Lilly, Johnson and Johnson and Warner Lambert). The key here is to see whether one or more attributes dominate Sullivan's DOIrank order. We have computed the average rank order for each of the variables in the three quadrants. It appears that the average belongingness to the clusters is decided by two variables: FSTS and FATA. 
It has been argued that an index like that of Sullivan's obscures the fact that one may get the same value of Internationalization for different values of Performance, Structure and Attitude leading to different kinds of multi-nationality (see, for instance, Ramaswamy, Kroeck and Renforth 1996).

We now turn to our ongoing studies of the multinational corporations where we will look at data for the Fortune 500 list of corporations.

\subsection{Case Study II: An HSOM Analysis of Fortune 100 Corporations}

Following a study of over 350 corporations listed in Fortune 500 list of 'top' corporations, Aggarwarl, Birrel and Kearney have devised a new MNC classification scheme. The attributes of these corporations were established by looking at how taxa are developed in agriculture, biology, chemistry, education, IT, Information Sciences, psychology and religion. Performance, structural and behavioural attributes were then outlined by Aggarwal et al (Table 2); there are similarities and differences with that of Sullivan's (Table 1).

Table 2. Classification attributes of corporations listed by Aggarwal et al

\begin{tabular}{|c|l|}
\hline Attributes & \multicolumn{1}{c|}{ Values } \\
\hline Performance & $\begin{array}{l}\text { Foreign Sales; Subsidiaries; Foreign Assets; Foreign Income; } \\
\text { Foreign Joint Ventures; Mergers \& Acquisitions; International } \\
\text { Transactions. }\end{array}$ \\
\hline Structural & $\begin{array}{l}\text { Global Accounts; Industry Details; Foreign Employees; For- } \\
\text { eign Equity; Foreign Exchange Listing. }\end{array}$ \\
\hline Behavioural & $\begin{array}{l}\text { World Mandates; Patents; Research \& Development; Foreign } \\
\text { Taxation; Unclear }\end{array}$ \\
\hline
\end{tabular}

The authors have re-interpreted the notion of multinationality operations performed by corporations either within or across countries and regions. They have created a 2x4 matrix, where rows label depth of engagement (through trade and investment), and columns label the breadth of the geographical spread (comprising domestic, regional, trans-regional and global breadths). This results in firms classified on a spectrum from purely domestic corporations to the deeply global ones. The authors suggest a 9-point scale in this respect over the space of 16 corporation types. Furthermore, Aggarwal et al's taxonomy distinguishes between publicly quoted corporations and state owned ones, and has used an industry classification - including finance \& insurance, information technology, manufacturing, retail, wholesale, and utilities. In their data set the authors have observed the uneven distribution of the 351 corporations across the 9-point multinationality spectrum: there are 171 corporations that trade and invest on a trans-regional basis, 89 have global investments and trade transregionally, 13 that do both globally, and there 27 exclusively domestic corporations. The location, age, and size are used as attributes in conjunction with others described above for 'computing' multinationality. Sullivan's attitudinal attributes are not used.

We trained an HSOM (10x10, 5X5 and 2x2 layers) with the data for the top 90 corporations listed in Fortune 500 and then tested the HSOM with 10 corporations. The training and testing samples were randomly selected by our program. The 10x10 
map shows clustering of corporations based on industry type and size. The next stage of clustering, the production of a $5 \times 5$ network, shows the size and industry variables forcing the clustering of the corporations.

We have observed the clustering effects growing as we traverse up the HSOM and finally the $2 \times 2$ map has had three clusters (Figure 3 ). We see that the top 10 corporations are located in $1^{\text {st }}$ quadrant of the map (00) which has 16 other corporations as well with ranks in the Fortune 500 list ranging from 23 to 88 . The feature vector for the manufacturing corporation, DaimlerChrysler, used for testing the efficacy of the HSOM was classified correctly with other large corporations in this quadrant which is also dominated by 16 manufacturing organisations. The $2^{\text {nd }}$ quadrant $(01)$ contains 50 corporations ranked 25 and 100, and is also dominated by manufacturers - the test vectors for the manufacturers Renault, Peugeot, and Sony are placed in this quadrant. The $3^{\text {rd }}$ quadrant (11) is dominated by finance and insurance corporations - 18 out of 20 corporations in our data have been assigned this industry type.

What is the role of the attributes related to the geographical breadth of the operations of the MNCs? The preponderance of the corporations with trans-regional sales (66 out of 100) has ensured that each of the quadrants has this type of corporation in it especially in the $2^{\text {nd }}$ quadrant (see Table 3 ). Nine out of eleven MNCs in our data set that have domestic sales only have been clustered in the $2^{\text {nd }}$ quadrant as well; the corporations that have global sales are mostly in the same quadrant. The $1^{\text {st }}$ quadrant has no global sales corporation and the third has no domestic sales corporations. Corporations with global and trans-regional subsidiaries are found in all the three quadrants with the $2^{\text {nd }}$ quadrant having $50 \%$ of the corporations in the two geographical breadth categories.

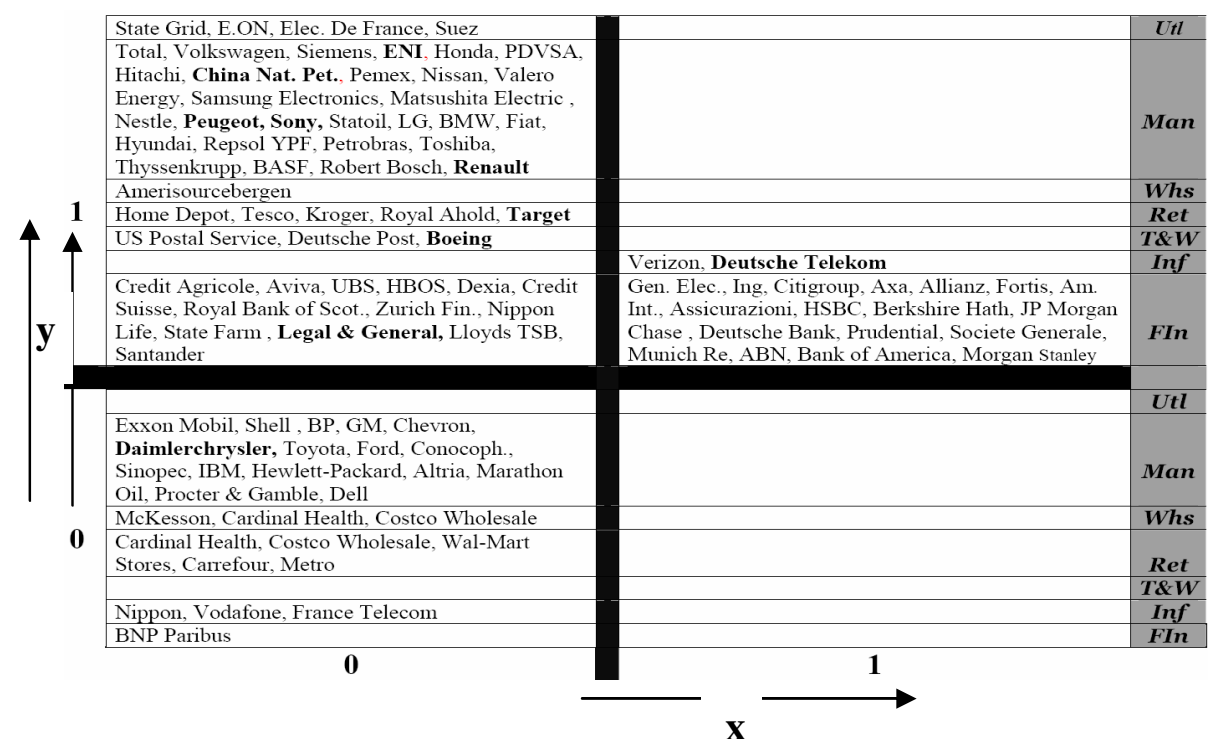

Fig. 3. An HSOM based classification of 90 Fortune 500 top corporation based on 7 attributes (public/private, industry code, age, size, location, and, the geographical spread of sales and subsidiaries). 10 other top corporations in the Fortune 500 list were used for testing and are shown in bold. The industry listing is provided for illustration only. 
Table 3. Classification of corporations in the $2 \times 2$ top layer of an HSOM

\begin{tabular}{|l|r|r|r|l|r|r|r|}
\hline \multicolumn{4}{|c|}{ Multinationality: Sales } & \multicolumn{4}{c|}{ Multinationality: Subsidiaries } \\
\hline Geog. Spread & 2X2 Map Coords. & Geog. Spread & \multicolumn{2}{|c|}{ 2X2 Map Coords } \\
\hline & $\mathbf{0 0}$ & $\mathbf{0 1}$ & $\mathbf{1 1}$ & & $\mathbf{0 0}$ & $\mathbf{0 1}$ & \multicolumn{1}{|c|}{} \\
\hline Global & 0 & $\mathbf{7}$ & 3 & Global & 12 & $\mathbf{1 6}$ & 8 \\
\hline Transnational & 24 & $\mathbf{3 6}$ & 16 & Transnational & 14 & $\mathbf{2 7}$ & 12 \\
\hline Regional & 0 & 2 & 1 & Regional & 0 & 2 & 0 \\
\hline Domestic & 2 & $\mathbf{9}$ & 0 & Domestic & 0 & $\mathbf{9}$ & 0 \\
\hline TOTAL & $\mathbf{2 6}$ & $\mathbf{5 4}$ & $\mathbf{2 0}$ & TOTAL & $\mathbf{2 6}$ & $\mathbf{5 4}$ & $\mathbf{2 0}$ \\
\hline
\end{tabular}

The corporations with domestic and regional subsidiaries only have been clustered in the $2^{\text {nd }}$ quadrant as well.

\section{Afterword}

We have attempted to demonstrate the utility of self-organising maps in general, and the hierarchical SOM's in particular, in a subject domain where the definition of an entity, the multi-national corporation, eludes the scholars. The hierarchical SOM generates not only a map, at the root SOM (10x10 in our case), but also what Vicente and Vellido (2008) have called an atlas at the top level (the $2 \times 2$ layer). We have seen the key attributes that were forcing the cluster formation in the case studies. The use of multinationality data, quantified through the use of sales and subsidiaries, requires further analysis, especially since our data set is dominated by trans-regional corporations.

The classification found in the 2x2 map, and indeed the other larger 5x5 and 10x10 maps, suggest that the two axes of the map may represent two conceptual variables that could be used to classify corporations, multinational or otherwise.

There is much room for improvement in our data sets. We are in the process of collating the data for all FORTUNE 500 corporations, but this effort is exacerbated by the fact that the data provided in the FORTUNE list has to be supplemented from the documents of each corporation individually for establishing, for example the geographical spread of sales and subsidiaries.

In terms of neural computing, the usage of growing HSOMs appears very attractive, especially when corporations with novel attributes come in the market place.

Acknowledgements. The authors wish to thank Donal Holland for helping with the layout and proof reading of the paper. Thanks are due to Maria F. O'Connor for help with the running of the self-organising maps.

\section{References}

1. Aggarwal, R., Berrill, J., Kearney, C.: A taxonomy of Multinationality: Towards a Classification System for MNCs (in preparation)

2. Ahmad, K., Vrusias, B., Ledford, A.: Choosing Feature Sets for Training and Testing SelfOrganising Maps: A Case Study. Neural Computing \& Applications 10, 56-66 (2001) 
3. Barry, F., Kearney, C.: MNEs and Industrial structure in Host Countries: A Portfolio Analysis of Irish Manufacturing. Journal of International Business Studies 37(3), 392-406 (2006)

4. Field, A.P.: Discovering Statistics using SPSS, 2nd edn., ch. 15. Sage, London

5. Lampinen, J., Oja, E.: Clustering properties of hierarchial self-organizing maps. Journal of Mathematical Imaging and Vision 2, 261-272 (1992)

6. Manomaisupat, P., Vrusias, B., Ahmad, K.: Categorization of Large Text Collections: Feature selection for unsupervised and supervised neural networks. In: Corchado, E., Yin, H., Botti, V., Fyfe, C. (eds.) IDEAL 2006. LNCS, vol. 4224, pp. 1003-1013. Springer, Heidelberg (2006)

7. McNeils, P.D.: Neural Networks in Finance - Gaining Predictive Edge in the Market. Elsevier, Amsterdam (2005)

8. Popoola, A., Ahmad, K.: Testing the Suitability of Wavelet Pre-processing for TSK Fuzzy Models. In: Proc. FUZZ-IEEE 2006: Int. Conference on Fuzzy Systems Networks, pp. 6655-6659 (2006)

9. Ramaswamy, K., Kroeck, K., Renforth, W.: Measuring the Degree of Internationalisation of a Firm: A Comment. Journal of International Business Studies 27(1), 167-177 (1996)

10. Sullivan, D.: Measuring the degree of internationalization of a firm. J. International Business Studies 25(2), 325-342 (1994)

11. Taskaya-Temizel, T., Casey, M., Ahmad, K.: Pre-processing inputs for optimally configured time-delay neural networks. IEE Electronics Letters 41(4), 198-200 (2005)

12. Vicente, L., Vellido, A.: Review of Hierarchical Models for Data Clustering and Visualization, 12 pages (visited August 21, 2008), http://www.1si.u.s.es/redmidas/ Capitulos/LMD20.pdf

13. Yu, L., Wang, S., Lai, K.K.: Neural network-based mean-variance-skewness model for portfolio selection. Computers and Operations Research 35(1), 34-46 (2008) 